\title{
A TEM STUDY OF CREEP DEFORMATION MECHANISMS IN ALLVAC 718PLUS
}

\author{
Raymond R. Unocic, ${ }^{1}$ Kinga A. Unocic, ${ }^{1}$ Robert W. Hayes, ${ }^{2}$ \\ Glenn S. Daehn, ${ }^{3}$ and Michael J. Mills ${ }^{3}$ \\ ${ }^{1}$ Oak Ridge National Laboratory, Oak Ridge, TN 37831 \\ ${ }^{2}$ Metals Technology Inc. Northridge, CA 91324 \\ ${ }^{3}$ The Ohio State University, Columbus, OH 43210
}

Keywords: Allvac 718Plus ${ }^{\mathrm{TM}}$, TEM, Creep Deformation Mechanisms

\begin{abstract}
A preliminary study on the evolution of creep deformation substructure in Ni-base superalloy Allvac 718Plus has been performed. Specimens crept at $620 \mathrm{MPa}$ and at temperatures ranging from $690-732^{\circ} \mathrm{C}$ were examined utilizing diffraction contrast TEM characterization techniques. Creep was interrupted at 1-2.5\% strain in order to study the deformation substructure following a limited amount of deformation. The dominant deformation modes at each of the test temperatures were highly planar in nature and involved shearing of the $\gamma$ matrix and $\gamma^{\prime}$ precipitates on $\{111\}$ glide planes. In addition, paired $\mathrm{a} / 2<110>$ dislocations were evident which suggest an antiphase boundary shearing mechanism. Creep induced microtwinning was also observed at the highest creep temperature which was created by identical $a / 6<112>$ Shockley partial dislocations that shear the $\gamma$ matrix and $\gamma^{\prime}$ precipitates on consecutive close packed $\{111\}$ glide planes.
\end{abstract}

\section{Introduction}

Ni-based superalloys are predominately utilized in aircraft and land-based industrial gas turbine engines where they excel in the retention of mechanical properties during service at elevated temperatures. In order to improve both engine performance and efficiency significant emphasis has been placed on developing alloys that can operate at higher temperatures without significant loss in structural integrity. In the conventional 718 alloy, the upper bound service temperature is limited to $\sim 650^{\circ}$, which is governed primarily by microstructural instability through coarsening of the prime strengthening $\mathrm{DO}_{22}$ structured $\mathrm{Ni}_{3} \mathrm{Nb}$-based $\gamma^{\prime \prime}$ precipitate phase followed by its transformation to the equilibrium orthorhombic $\mathrm{Ni}_{3} \mathrm{Nb} \delta$-phase [1-6]. With this in mind, Allvac 718Plus was developed with the specific goal of increasing the temperature capability by $\sim 55^{\circ} \mathrm{C}$ while maintaining the excellent workability and weldability characteristics of 718 [7-8]. The alloy chemistry was modified such that the Fe content was reduced while the $\mathrm{W}$, Co and $\mathrm{Al} / \mathrm{Ti}$ ratio was increased. This combination of changes enables the precipitation of ordered $\mathrm{L} 1_{2}$ structured $\left(\mathrm{Ni}_{3} \mathrm{Al}, \mathrm{Ti}\right)$ based $\gamma^{\prime}$ precipitates that are coherently embedded in a solid solution $\gamma$ matrix [9-10]. It is expected that the alteration of the prime-strengthening constituent from $\gamma^{\prime \prime}$ to $\gamma^{\prime}$ will have a significant effect on the thermal stability of this alloy as well as the high temperature mechanical properties.

In Ni-based superalloys where $\gamma^{\prime}$ is the prime-strengthening phase, a rich variety of deformation modes have been reported [11-18]. The precipitates themselves are unique in that during deformation, the $\gamma^{\prime}$ precipitates impart resistance to plastic deformation since they act as effective 
barriers to dislocation motion as high energy atomic configurations would develop if the precipitates were to be sheared by perfect or partial dislocations operating on $<110>\{111\}$ or $<112>\{111\}$ slip systems, respectively. Examples of these structural and chemical defects include antiphase boundaries (APB), complex stacking faults (CSF), superlattice intrinsic stacking faults (SISF), or superlattice extrinsic stacking faults (SESF). Since these alloys are expected to operate at high temperature and high stress regime where creep deformation is of concern it is important to characterize the thermally activated, creep rate controlling deformation mechanisms. Although baseline mechanical property testing has already been performed on Allvac 718Plus, there has yet to be a detailed study on the deformation mechanisms in this alloy system. In this study, we have investigated the creep deformation mechanisms of Allvac 718Plus at three different temperatures through analysis of the deformation substructure using diffraction contrast TEM characterization techniques.

\section{Materials and Experimental Procedure}

The Allvac 718Plus material used in this creep deformation study was provided in the solution heat-treated form. The microstructure consists of equiaxed grains with a fair amount of annealing twins as shown in light optical micrographs presented in Figure 1. When viewed at higher magnification, it can be seen that the grain boundaries are decorated with the thin needle shaped $\delta-\mathrm{Ni}_{3} \mathrm{Nb}$ grain boundary phase. The high temperature creep properties were studied through constant load tensile creep tests in air at $620 \mathrm{MPa}$ and at test temperatures of: 691, 704 and $732^{\circ} \mathrm{C}$. Specimens were crept to a minimal amount if deformation (1-2.5\%) then cooled under load which enabled the deformation substructure to be characterized. Following creep, a detailed TEM characterization study of the deformation mechanisms was performed using a $\mathrm{LaB}_{6}$ FEI Tecnai TEM operating at $200 \mathrm{keV}$. Specimens for TEM characterization were extracted from the gauge section at a $45^{\circ}$ angle with respect to the tensile axis in order to facilitate TEM characterization of defects on slip planes that experienced maximum shear stress. Specimens were mechanically thinned using progressively finer SiC paper to 1200 grit then slurry drilled to create $3 \mathrm{~mm}$ disks. Final thinning to electron transparency was performed using a Struers Tenupol 5 twin jet electropolisher using an electrolyte consisting of 60\% Methanol, 35\% 2-nbutoxyethanol, and $5 \%$ perchloric acid at $-40^{\circ} \mathrm{C}$ and $15 \mathrm{~V}$.

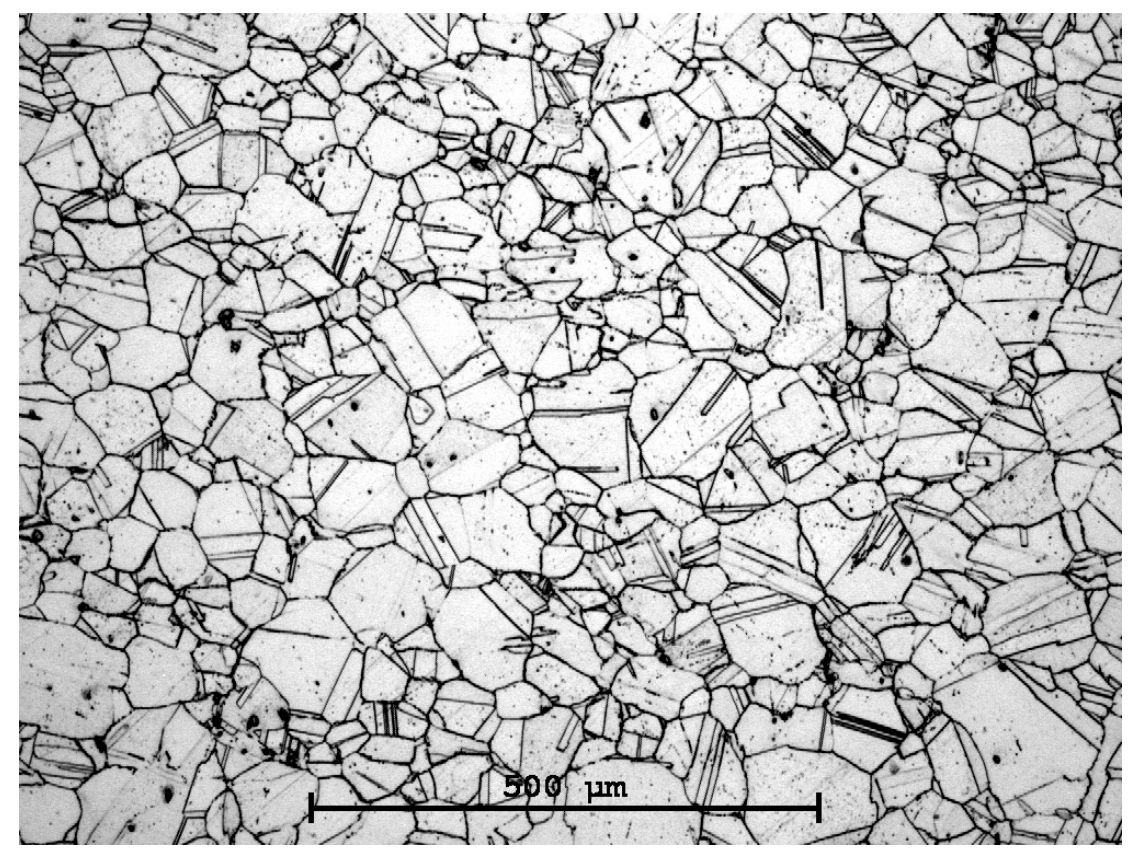




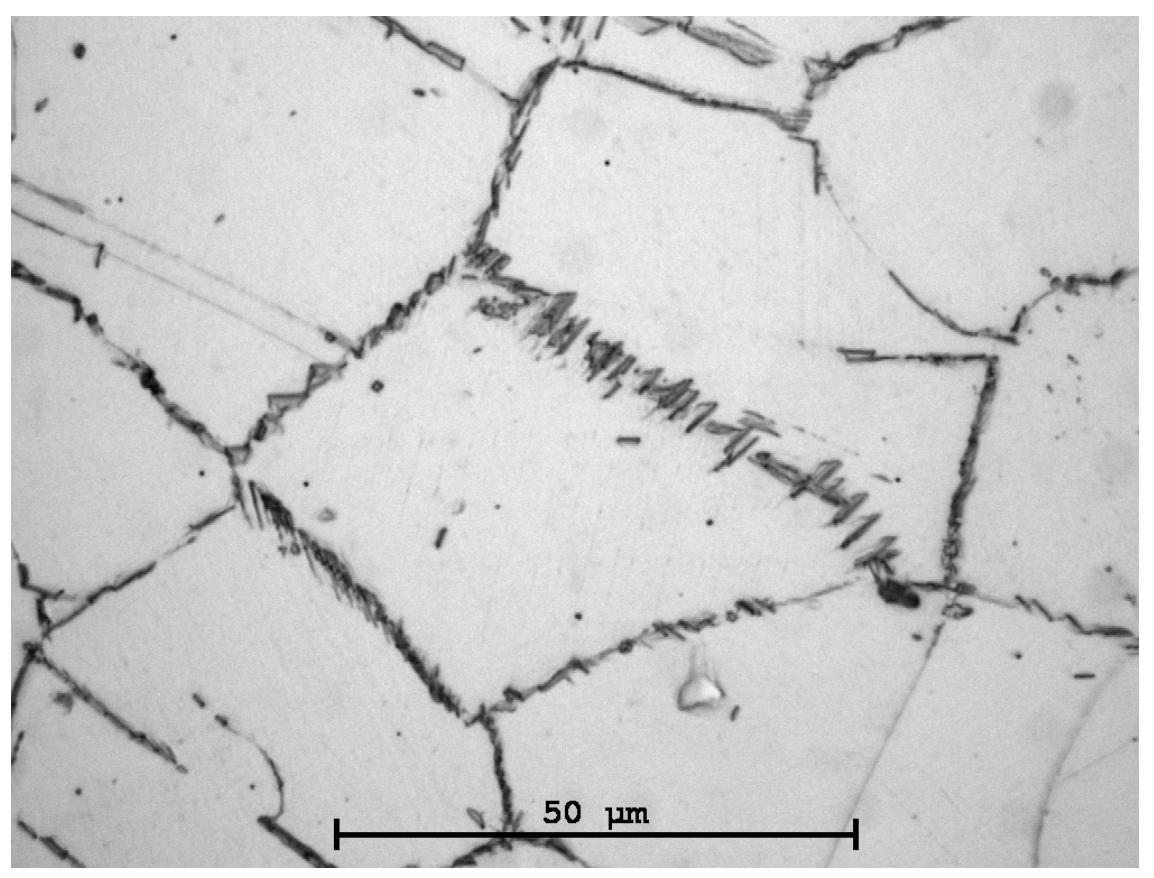

Figure 1. Light optical micrographs of solution heat treated Allvac 718Plus a) lower magnification image revealing equiaxed grains with $\Sigma 3$ annealing twin boundaries and b) higher magnification image revealing the presence of grain boundary $\delta-\mathrm{Ni}_{3} \mathrm{Nb}$ phase.

\section{Results and Discussion}

The macroscopic creep deformation response of Allvac 718Plus is presented in creep strain vs time curves in Figure 2. The influence of temperature on creep can easily be deduced as specimens were crept at the same stress $(620 \mathrm{MPa})$ but at different test temperatures (691, 704 and $732^{\circ} \mathrm{C}$ ). As expected, with increasing temperature there is a noticeable difference in creep rate. At the lowest test temperature a small primary creep transient period does exist which is followed by a steady state creep regime. After about 125 hours there is an inflection in the creep curve where the creep rate begins to accelerate indicating a transition from secondary to tertiary creep. At the intermediate test temperature there is no such pronounced steady state creep regime and the creep behavior seams to transition directly from primary to tertiary creep. Creep at the highest test temperature appears to exhibit nearly entirely tertiary creep behavior and reaches 1\% creep strain in a relatively short amount of time. 


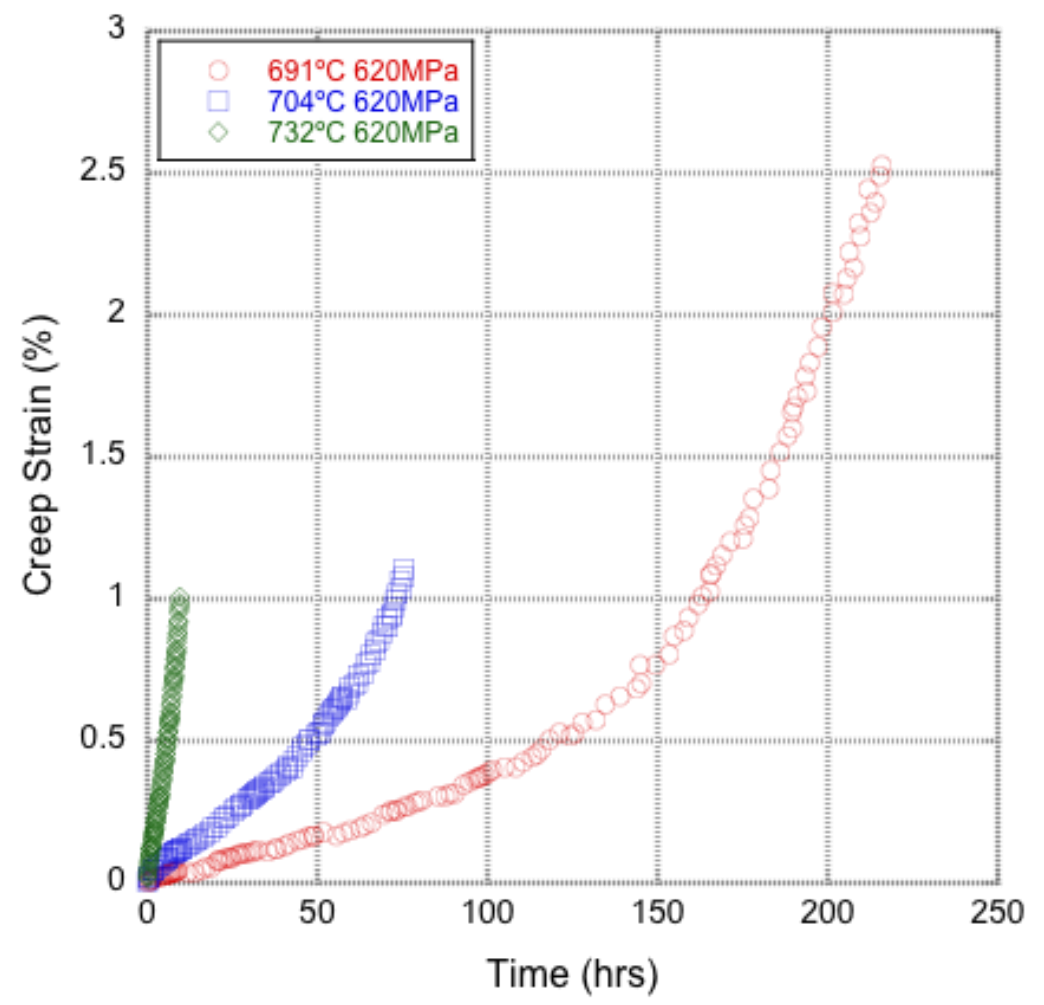

Figure 2. Interrupted creep curves showing plastic strain vs. time for Allvac 718Plus crept at 620 $\mathrm{MPa}$ and at 691,704 , and $732^{\circ} \mathrm{C}$.

In order to better understand the creep rate controlling processes and to correlate the creep response to the underlying creep deformation mechanisms, TEM characterization of the deformation substructure was conducted. When the deformation substructure was analyzed following creep at $691^{\circ} \mathrm{C}$, deformation appears to be initiated from grain boundary sources as shown in Figure 3a. In some cases the grain boundary $\delta$ phase appears to be the initiation sites for deformation activity. It is unclear however whether the grain boundaries themselves or the grain boundary delta phase act as stress concentrators in this material. Nevertheless, the dominant deformation structures are highly planar faulted structures that exist on multiple slip systems. Slip trace analysis has confirmed that slip is restricted to the close packed \{111\} glide planes. When the planar deformation structures are inclined with respect to the electron beam it can be seen that the $\gamma^{\prime}$ precipitates have been sheared as marked by the continuous stacking faults that transcend through both the $\gamma$ matrix and $\gamma^{\prime}$ precipitate. Aside from these dominant stacking fault relating shearing modes, loosely-coupled, paired $\mathrm{a} / 2<110>$ type matrix dislocations are also involved in the deformation processes, albeit to a lesser degree. This is indicative of the coupled $\mathrm{a} / 2<110>$ APB shearing mode where the leading dislocation shears the $\gamma^{\prime}$ precipitate, creating a high energy APB. The order of the $\gamma^{\prime}$ precipitate is then restored as the trailing a/2<110> dislocations shears the $\gamma^{\prime}$.

During creep at $704^{\circ} \mathrm{C}$, deformation again is dominated by highly planar stacking fault shearing configurations where they are observed to extend across entire grains as shown in Figure 4a. These mechanisms are similar to the stacking fault related shearing processes as observed in the specimen crept at $691^{\circ} \mathrm{C}$. Further detailed dislocation and stacking fault analysis is still needed for the specimens crept at 691 and $704^{\circ} \mathrm{C}$ in order to determine what type of dislocations are responsible for the stacking fault related shearing mode and whether or not the stacking faults 
created in its wake are intrinsic or extrinsic in nature. With this information it would then be possible to adequately describe the deformation mechanism and determine what the creep rate limiting process. Aside from the planar stacking fault-shearing mode, the motion of a/2<110 $>$ dislocations that are locally dissociated into a/6 $<112>$ type Shockley partial dislocations and separated by the matrix intrinsic-stacking fault. (Refer to Figure 4b). The process by which these dislocations dissociate into Shockley partial dislocations have previously studied in polycrystalline Ni-based superalloys through in-situ and post mortem TEM characterization where it was determined that a narrow $\gamma$ channel width (distance between $\gamma^{\prime}$ precipitates) promotes the dislocation dissociation process [19].

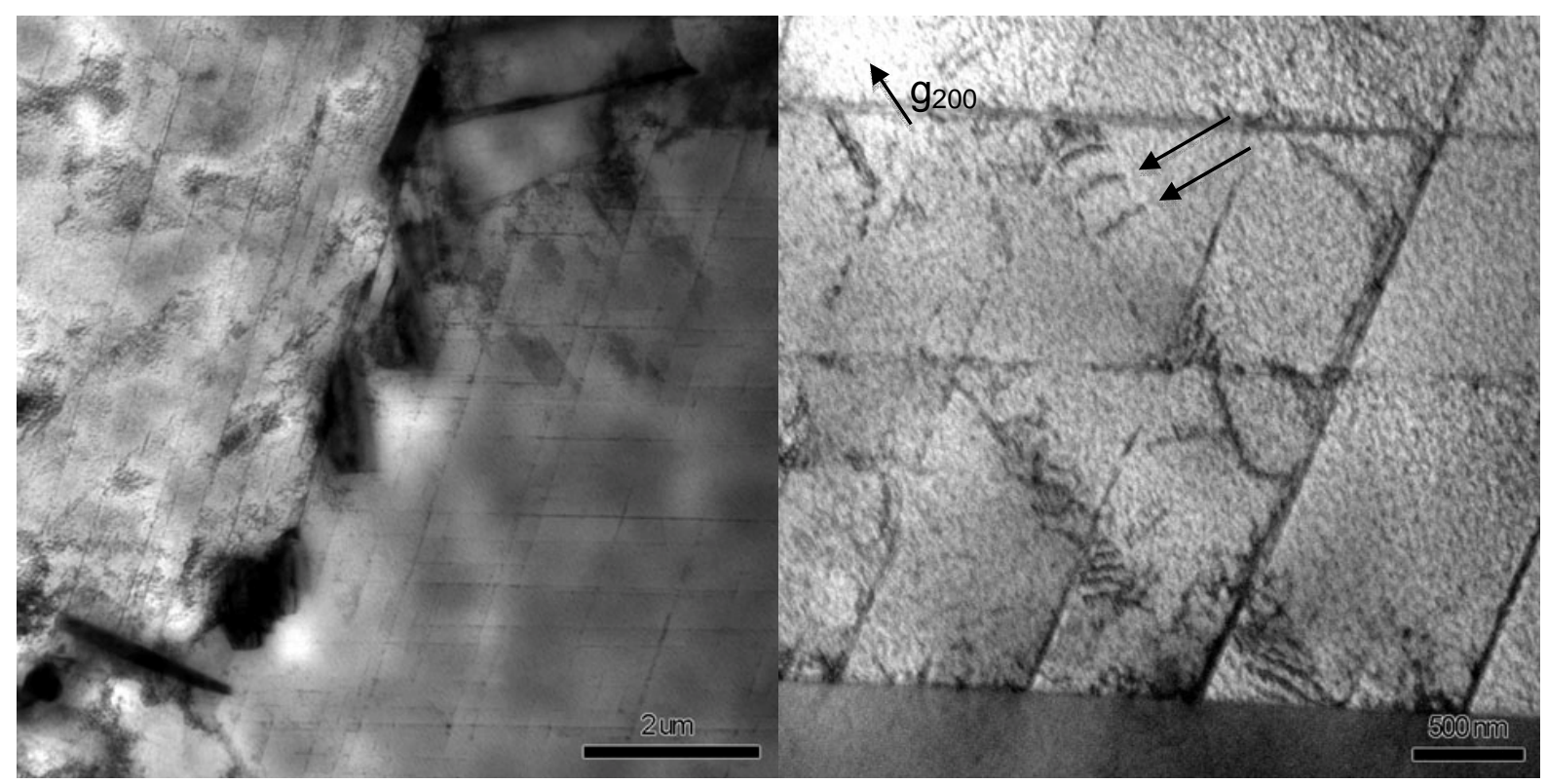

Figure 3. Bright field TEM micrographs of specimen crept at $620 \mathrm{MPa}$ and $691^{\circ} \mathrm{C}$ depicting a) planar type stacking fault shearing configurations initiating from grain boundary $\delta$ precipitates as the dominant deformation mechanisms and b) a/2<110> matrix dislocations (as marked by arrows).
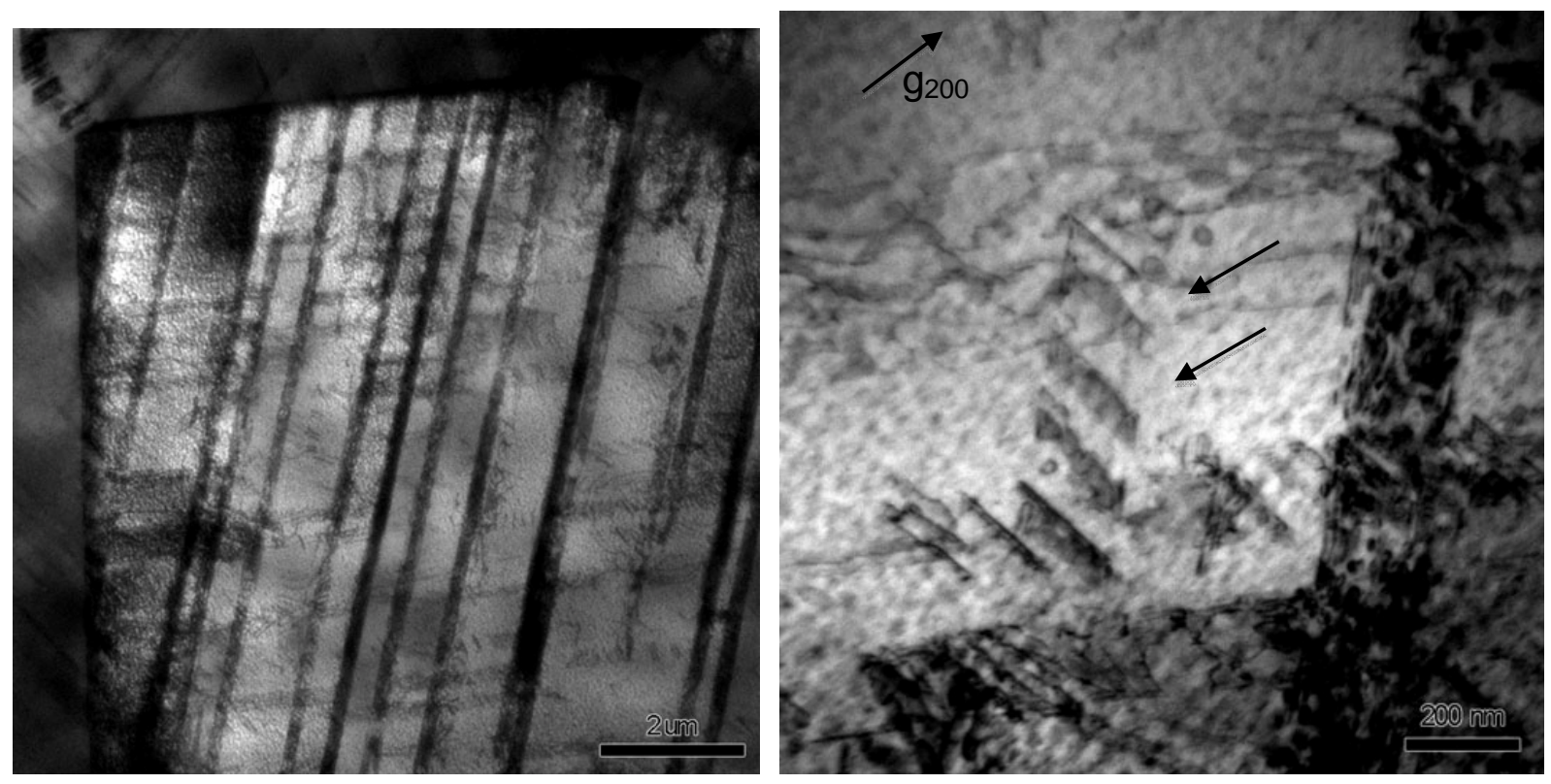
Figure 4. a) Planar stacking fault related shearing mechanisms developed during creep at $620 \mathrm{MPa}$ and $704^{\circ} \mathrm{C}$ and b) loosely coupled $\mathrm{a} / 2<110>$ dislocations which appear to be locally dissociated into a/6 $<112>$ Shockley partial dislocations separated by stacking faults (as marked by arrows).

During creep at the highest test temperature examined in this study $\left(732^{\circ} \mathrm{C}\right)$ a high density of continuous planar faulted structures that shear through both the $\gamma$ matrix as well as the $\gamma^{\prime}$ precipitates were also observed. A representative image of these structures imaged in an edge on orientation is shown in Figure 5a along with a selected area electron diffraction pattern (SAED) acquired about the [011] zone axis (Figure 5b). In the SAED pattern, there are fundamental reflections associated with the matrix and superlattice reflections associated with the $\gamma^{\prime}$ precipitates. Additionally, there are extra twin reflections that are present, which provides direct evidence that these highly planar faulted structures are microtwins. The appearance of microtwins during creep in Ni-based superalloys have been reported in both polycrystalline disk and single crystal blade alloys [17-21]. One of the earliest experimental evidence of microtwinning in a $\gamma^{\prime}$ strengthened Ni-base Superalloy was reported by Guimier and Strudel in Waspaloy deformed above $500^{\circ} \mathrm{C}$ [20]. Electron diffraction experiments showed the presence of twin reflections and superlattice reflections and thus was reported that the ordered structure of the $\gamma^{\prime}$ precipitates has been maintained after twinning. Kakehi proposed a mechanism that may lead to the formation of microtwins by superpartial dislocation shear and superlattice stacking fault formation. It was proposed that when the (c) 2 precipitates are sheared by $a / 3<112>$ superlattice Shockley partials on adjacent $\{111\}$ planes, an SISF would form on the first layer, SESF on the second layer, and a twin on successive layers [21]. In the $\mathrm{L} 1_{2}$ structure of the $\gamma^{\prime}$ precipitates, this would result in twin formation if the $a / 3<112>$ partial dislocations shear the precipitate on adjacent $\{111\}$ glide planes. Although this mechanism seems quite feasible since it accounts for the ordered $\mathrm{L} 1_{2}$ structure to be preserved, shearing the crystal by such a large displacement would require high stresses. Since then, little attention has been given until recently since it seems that this mechanism is highly dependent upon alloy chemistry, $\gamma^{\prime}$ precipitate size scale/morphology, $\gamma$ channel spacing, orientation, stress, and temperature.

On the other hand Kolbe has proposed a hypothesis that microtwins can form by the pairwise passage of identical a/6<112> Shockley partial dislocations that shear through both $\gamma$ and $\gamma^{\prime}$ on adjacent $\{111\}$ glide planes [22]. Taking into consideration that shearing of the $\gamma^{\prime}$ precipitate by a single $a / 6<112>$ Shockley partial dislocation would result in a high energy CSF. Kolbe proposed that diffusion mediated atomic reordering in the wake of the leading partials is required to convert the pseudotwin structure created in the $\gamma^{\prime}$ into a true twin structure with reshuffling of atoms to establish the correct nearest $\mathrm{Ni}$-Al neighbor bonds as that in the $\mathrm{L}_{2}$ ordered $\gamma^{\prime}$ structure. Although direct TEM evidence was not given at the time, it has been later substantiated through direct TEM evidence that microtwins do actually form when both the $\gamma$ matrix and $\gamma^{\prime}$ precipitates are sheared conservatively by identical, paired $a / 6<112>$ Shockley partial dislocations traveling on adjacent type octahedral glide planes [17]. In a recent review on microtwinning in Ni-based superalloys by Kovarik et al [23], it was reported that thermallyactivated, diffusion-based atomic reordering is the rate limiting process in the progression of creep induced microtwinning and that it is energetically feasible to occur by vacancy mediated exchange mechanism between $\mathrm{Al}$ and $\mathrm{Ni}$ which is facilitated by the higher diffusion rates during creep at elevated temperature. 

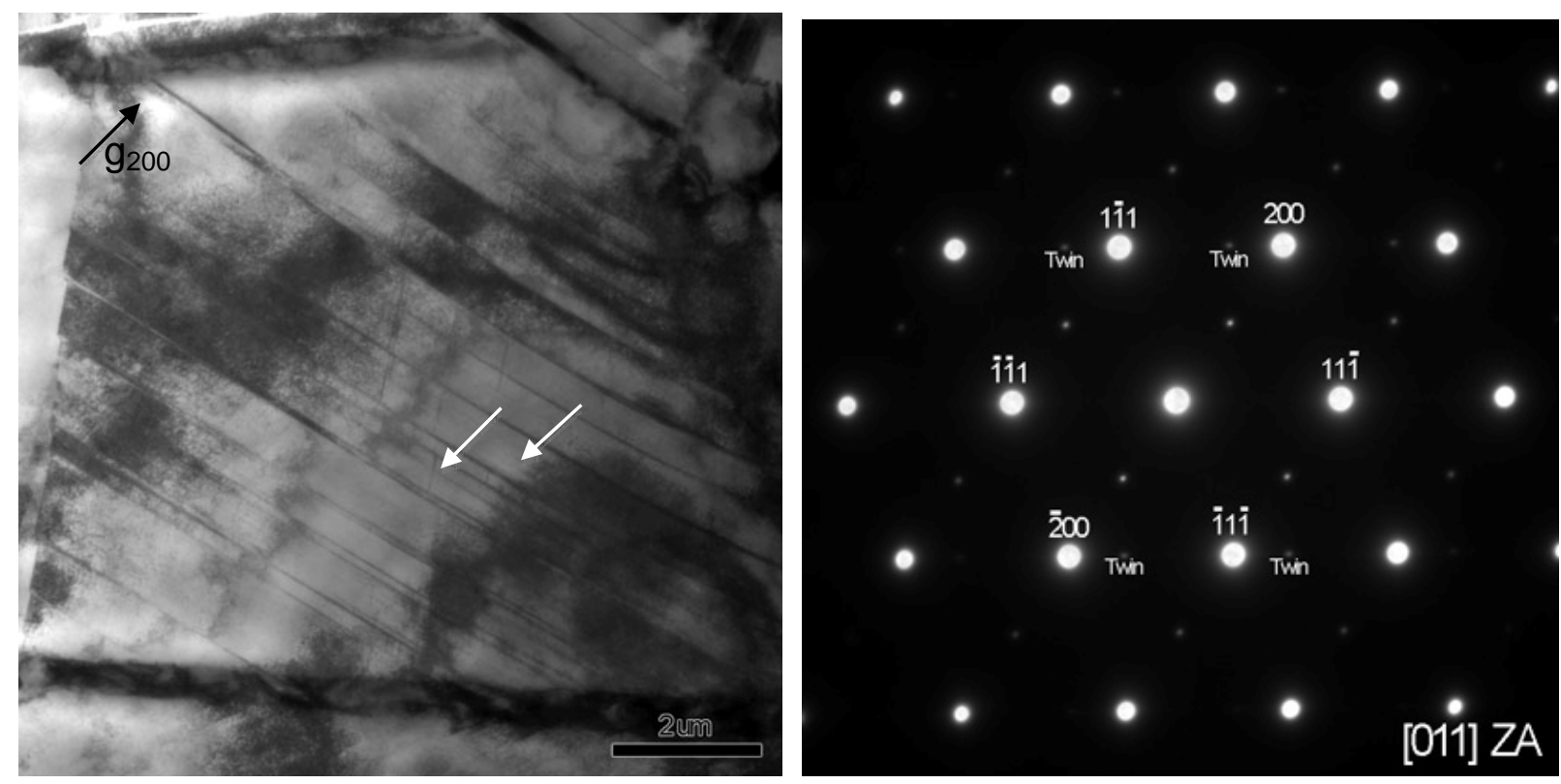

Figure 5. a) Bright field TEM image of highly planar microtwins (as marked by arrows) imaged edge on formed during creep at $620 \mathrm{MPa}$ and $732^{\circ} \mathrm{C}$. The presence of twin reflections in the selected area electron diffraction pattern in b) provides confirmation that the highly planar shearing configurations are microtwins.

\section{Conclusions}

The high temperature creep deformation mechanisms of Allvac 718Plus was evaluated through TEM characterization of specimens crept at the same stress $(620 \mathrm{MPa})$ but at different temperatures $\left(691-732^{\circ} \mathrm{C}\right)$ in order to determine the effect of temperature on creep deformation behavior and underlying creep deformation mechanisms. For all test conditions, very highly planar deformation structures were prevalent as a major source of deformation; however there were clear distinctions between the thermally activated shearing configurations. At the lower test temperatures deformation involves shearing of the $\gamma$ matrix and $\gamma^{\prime}$ precipitates by partial dislocations through a stacking fault related shearing mode. At the highest test temperature, microtwinning was observed and is created by the passage of paired Shockley partial dislocations. Following precipitate shear by partial dislocations, the thermally activated rate controlling process in each of these deformation modes is suggested to be related to atomic reordering within the $\gamma^{\prime}$ precipitates. Considering the aforementioned deformation mechanisms, these results should provide further insight into the thermally activated deformation processes that occurs during creep of $\gamma^{\prime}$ strengthened Allvac 718Plus.

\section{Acknowledgements}

Microscopy research was supported in part by Oak Ridge National Laboratory (ORNL) Shared Research Equipment (SHaRE) User Facility, which is sponsored by the Scientific User Facilities Division, Office of Basic Energy Sciences, U.S. Department of Energy (DOE).

\section{References}


1. H. F. Merrick, Precipitation Process in Solids, TMS-AIME, (1978), 161-190.

2. M. Sundararaman, P. Mukhopadhyay and S. Banerjee, Metallurgical Transactions A 19A (1988), 453-465.

3. M. Sundararaman, P. Mukhopadhyay and S. Banerjee, Metallurgical Transactions A 23A (1992), 2015-2028.

4. J. P. Collier, S. H. Wong, J. C. Phillips and J. K. Tien, Metallurgical Transactions A 19A (1988), 1657-1666.

5. J. P. Collier, A. O. Selius and J. K. Tien, , Superalloys (1988), 43-52.

6. M. Sundararaman and P. Mukhopadhyay, Defect and Diffusion Forum 213-215 (2003), 61-74.

7. W. D. Cao and R. L. Kennedy, Superalloys 2004, ed. K.A. Green et al., TMS (2004), 91-99.

9. W. D. Cao, TMS (The Minerals, Metals \& Materials Society): Superalloys 718, 625, 706 and Derivatives (2005), 165-177.

10. R. Cozar and A. Pineau, Metallurgical Transactions A 4 (1973), no. 1, 47-59.

11. G.R. Leverant, B.H. Kear, J.M. Oblak. Metallurgical Transactions, 2, (1971) 2305.

12. Q.Z. Chen, D.M. Knowles, Materials Science \& Engineering, A: Structural Materials: Properties, Microstructure and Processing, A356, (2003), 352.

13. D. Locq, P. Caron, S. Raujol, F. Pettinari-Sturmel, A. Coujou, N. Clement Superalloys 2004, Proceedings of the International Symposium on Superalloys, 10th, Champion, PA, United States, Sept. 19-23, 2004, 179.

14. T. Link, M. Feller-Kniepmeier, Metallurgical Transactions A: Physical Metallurgy and Materials Science, 23A, (1992), 99.

15. P. Caron, T. Khan, P. Veyssiere. Philosophical Magazine A: Physics of Condensed Matter: Structure, Defects and Mechanical Properties, 57, (1988), 859.

16. Y.Z. Zhang, QZ Chen, DM Knowles. Materials Science and Technology, 17, (2001) 1551.

17. G.B. Viswanathan, P.M. Sarosi, M.F. Henry, D.D. Whitis, W.W. Milligan, M.J. Mills, Acta Materialia, 53, (2005), 3041-3057.

18. R.R. Unocic, L. Kovarik, C. Shen, P.M. Sarosi, Y. Wang, J. Li, S. Ghosh and M.J. Mills, Superalloys 2008 (TMS, Warrendale, 2008), edited by Roger C. Reed, Kenneth A. Green, Pierre Caron, Timothy P. Gabb, Michael G. Fahrmann, Eric S. Huron, and Shiela A. Woodard, 377386, (2008).

19. S. Raujol, M. Benyoucef, D. Locq, P. Caron, F. Pettinari, N. Clement, A. Coujou, Philosophical Magazine, 86, 9, (2006), 1189-1200. 
20. A. Guimier A, J.L. Strudel, $2^{\text {nd }}$ Int. Conf. Strength Metals Alloys, Conf. Proc. (1970), 1145.

21. K. Kakehi, Metallurgical and Materials Transactions A, 30A, (1999), 1249.

22. M. Kolbe, Materials Science \& Engineering A, A319-321, (2001), 383.

23. L. Kovarik, R.R. Unocic, J. Li, P. Sarosi, C. Shen, Y. Wang, M.J. Mills, Progress in Materials Science, 54, (2009), 839-893. 